\title{
Drug-Susceptible and Multidrug-Resistant Mycobacterium tuberculosis in a Single Patient
}

\section{Anthony Baffoe-Bonnie, Eric R. Houpt, Lauren Turner, Denise Dodge, Scott K. Heysell}

Author affiliation: Virginia Polytechnic Institute and State University Carilion School of Medicine, Roanoke, Virginia, USA (A. Baffoe-Bonnie); University of Virginia, Charlottesville, Virginia, USA (E.R. Houpt, S.K. Heysell); Division of Consolidated Laboratory Services, Richmond, Virginia, USA (L. Turner); Virginia Department of Health, Richmond (D. Dodge)

DOI: https://doi.org/10.3201/eid2511.180638

A patient who had initial infection with mixed strains of drug-susceptible and multidrug-resistant tuberculosis was presumed to have acquired drug resistance before confirmation that sequential strains were genotypically distinct. Transmitted infection with mixed strains is likely underappreciated; identifying these infections requires spoligotyping and whole-genome sequencing.

$\mathrm{M}$ ultidrug-resistant (MDR) tuberculosis (TB), defined as infection with Mycobacterium tuberculosis that is resistant to isoniazid and rifampin, can be transmitted and manifest as a primary infection without a patient having received those medications or can be acquired by the patient during drug therapy. A person may be initially infected with $\geq 1 M$. tuberculosis strain with different patterns of drug resistance (1-4). We present such a case, which is likely uncommon but underappreciated; identification requires spoligotyping and whole-genome sequencing of sequential strains.

A 28-year-old man came to a hospital in Virginia, 1 year after immigrating from the Philippines, with a 4-week history of fevers, night sweats, weight loss, voice change, and cervical lymphadenopathy. A computed tomography scan showed no lung parenchymal or pleural abnormality. Cervical lymph node biopsy showed caseating granulomas with acid-fast bacilli (AFB). Sputum smears demonstrated 4+ AFB. Rapid nucleic acid amplification testing by commercial line probe assay confirmed $M$. tuberculosis complex from both sites without rpoB, $k a t G$, or inhA mutation. Test results for HIV were positive; HIV viral load was 521,800 copies $/ \mathrm{mL}$ and CD4 count 7 cells $/ \mathrm{mm}^{3}$. Diagnoses were made of TB lymphadenitis and presumed laryngeal TB. We started the patient on antiretroviral drugs after initiating isoniazid, rifampin, ethambutol, and pyrazinamide. Phenotypic testing ultimately showed susceptibility to isoniazid, rifampin, ethambutol, and pyrazinamide. The patient achieved sputum culture conversion to negative before beginning his eighth week of treatment and transitioned to a continuation phase of isoniazid and rifampin 5 days/week.

Twenty weeks into treatment, the patient's sputum AFB culture obtained 12 weeks after initiation was reported as positive. Given this relapse, we conducted therapeutic drug monitoring for isoniazid and rifampin. Estimated peak serum drug concentrations were 2.07 (range $3-5$ ) $\mu \mathrm{g} / \mathrm{mL}$ for isoniazid and 5.98 (range $8-24) \mu \mathrm{g} / \mathrm{mL}$ for rifampin. Molecular sequencing of the week $12 \mathrm{M}$. tuberculosis isolate at the Centers for Disease Control and Prevention (5) found mutations in $r p o B$ (GACCAG $>\mathrm{GAG}$; Asp516Gln517Glu) and inhA $(\mathrm{C}-15 \mathrm{~T})$, but the subsequently tested pretreatment sputum isolate was confirmed negative for mutations in the resistance-determining regions of $r p o B$ (rifampin), $k a t G$ and $\operatorname{inh} A$ (isoniazid), and $p n c A$ (pyrazinamide). Both isolates had mutations in the embB gene Leu355Leu (silent) and Glu378Ala (reported as unlikely to cause resistance alone and, more commonly, a marker of Indo-Oceanic strain lineage) (6). We switched the patient's drug regimen to levofloxacin, linezolid, capreomycin, para-aminosalicylate, ethambutol, and pyrazinamide. Phenotypic susceptibility tests later confirmed MDR TB: $25 \%$ resistance to isoniazid at $1.0 \mu \mathrm{g} / \mathrm{mL}$ and $100 \%$ resistance to rifampin at $1.0 \mu \mathrm{g} / \mathrm{mL}$. The patient continued with this MDR TB regimen for 15 months after culture conversion to negative. He has remained healthy.

We clinically interpreted this scenario as one of acquired drug resistance, likely contributed by the subtarget concentration of anti-TB drugs. However, analyses of mycobacterial interspersed repetitive unit-variable-number tandem-repeat typing, along with insertion sequence 6110 restriction fragment length polymorphism analyses of the pretreatment drug-susceptible strain and the week 12 MDR strain, showed distinct spoligotypes. Whole-genome sequencing differed by $>100$ single nucleotide polymorphisms, supporting that these strains were genotypically distinct. Upon further questioning, the patient related that before immigrating he lived in a small apartment in Manila where friends and family would frequently lodge before seeking treatment at the city's referral hospital.

Prior treatment with isoniazid and rifampin is a major risk factor for MDR TB. Comprehensive epidemiologic studies and improved access to whole-genome sequencing have revealed that primary MDR TB transmitted to the patient can be common (7). Our case adds to the literature on transmitted MDR TB dynamics and shows how initial infections with mixed strains may be an underreported cause of treatment failure. The clonal diversity from a M. tuberculosis sample is clearly attenuated following conventional culture techniques on solid agar (8). Although heteroresistance at drug-resistant loci of $M$. tuberculosis can be detected at low levels with newer next-generation sequencing 
Table. Characteristics of cases of treatment failure resulting from concurrent infection with mixed strains of drug-resistant Mycobacterium tuberculosis*

\begin{tabular}{|c|c|c|c|c|c|c|c|}
\hline $\begin{array}{l}\text { Patient } \\
\text { age, y/sex }\end{array}$ & Immune status & $\begin{array}{l}\text { Site(s) of } \\
\text { infection }\end{array}$ & $\begin{array}{l}\text { Time to } \\
\text { recurrence }\end{array}$ & $\begin{array}{l}\text { Platform for strain } \\
\text { identification }\end{array}$ & $\begin{array}{c}\text { Patient country } \\
\text { of origin }\end{array}$ & $\begin{array}{l}\text { Country of } \\
\text { diagnosis }\end{array}$ & Reference \\
\hline $24 / \mathrm{M}$ & Immunocompetent & $\begin{array}{l}\text { Lymph node, } \\
\text { gastric aspirate }\end{array}$ & $100 \mathrm{~d}$ & $\begin{array}{c}\text { Mixed-linker } \\
\text { fingerprint PCR }\end{array}$ & Nepal & Germany & $(1)$ \\
\hline 23/M & HIV negative & Pulmonary & $150 \mathrm{~d}$ & $\begin{array}{c}\text { Spoligotyping and } \\
\text { MIRU }\end{array}$ & Somalia & USA & (4) \\
\hline 24/M & HIV negative & $\begin{array}{l}\text { Pulmonary, } \\
\text { gastric aspirate }\end{array}$ & $90 \mathrm{~d}$ & $\begin{array}{l}\text { IS6110 RFLP and } \\
\text { spoligotyping }\end{array}$ & Kazakhstan & Germany & (2) \\
\hline $62 / \mathrm{M}$ & HIV negative & Pulmonary & $120 d$ & MIRU-VNTR & Portugal & UK & (3) \\
\hline 28/M & HIV positive & $\begin{array}{l}\text { Lymph node, } \\
\text { trachea }\end{array}$ & $84 \mathrm{~d}$ & $\begin{array}{c}\text { Spoligotyping and } \\
\text { WGS }\end{array}$ & Philippines & USA & This study \\
\hline
\end{tabular}

techniques from cultured growth, these analyses cannot distinguish infection with multiple strains from heteroresistance among subpopulations of the same strain (9).

As with the previous cases (1-4) of mixed-strain infection, the patient we report did not have prior history of TB treatment and showed initial improvement but then had a recrudescence of symptoms and culture reversion 115 days into first-line therapy (range 90-150 days in previously reported cases) (Table). Applying whole-genome sequencing to additional samples collected from our patient and meticulous isolation of different colonies of cultured growth might have detected heteroresistance, and consequent alteration of the initial treatment regimen could have prevented the recrudescence of disease. However, the detection of lower-level genetic heteroresistance has not been rigorously studied for its effect on populations of persons initiating TB treatment and will undoubtedly vary based on the drug-specific locus that is heteroresistant and the quantitative level of detection. Well-curated prospective cohorts that contribute sequencing data may refine our understanding of this effect but will require nuanced bioinformatics (10).

\section{Acknowledgments}

The authors thank Beverly Metchock and James Posey for consultation regarding $M$. tuberculosis sequencing results.

\section{About the Author}

Dr. Baffoe-Bonnie is an infectious diseases practitioner at Carilion Roanoke Memorial Hospital, Roanoke, VA, USA. His research interests include tuberculosis management, HIV, and immigrant health.

\section{References}

1. Theisen A, Reichel C, Rüsch-Gerdes S, Haas WH, Rockstroh JK, Spengler U, et al. Mixed-strain infection with a drug-sensitive and multidrug-resistant strain of Mycobacterium tuberculosis. Lancet. 1995;345:1512-3. https://doi.org/10.1016/S0140-6736(95)91073-5
2. Niemann S, Richter E, Rüsch-Gerdes S, Schlaak M, Greinert U. Double infection with a resistant and a multidrug-resistant strain of Mycobacterium tuberculosis. Emerg Infect Dis. 2000;6:548-51. https://doi.org/10.3201/eid0605.000518

3. Hingley-Wilson SM, Casey R, Connell D, Bremang S, Evans JT, Hawkey PM, et al. Undetected multidrug-resistant tuberculosis amplified by first-line therapy in mixed infection. Emerg Infect Dis. 2013;19:1138-41. https://doi.org/10.3201/eid1907.130313

4. Mendez MP, Landon ME, McCloud MK, Davidson P, Christensen PJ. Co-infection with pansensitive and multidrugresistant strains of Mycobacterium tuberculosis. Emerg Infect Dis. 2009;15:578-80. https://doi.org/10.3201/eid1504.080592

5. Yakrus MA, Driscoll J, Lentz AJ, Sikes D, Hartline D, Metchock B, et al. Concordance between molecular and phenotypic testing of Mycobacterium tuberculosis complex isolates for resistance to rifampin and isoniazid in the United States. J Clin Microbiol. 2014;52:1932-7. https://doi.org/10.1128/ JCM.00417-14

6. Campbell PJ, Morlock GP, Sikes RD, Dalton TL, Metchock B, Starks AM, et al. Molecular detection of mutations associated with first- and second-line drug resistance compared with conventional drug susceptibility testing of Mycobacterium tuberculosis. Antimicrob Agents Chemother. 2011;55:2032-41. https://doi.org/ 10.1128/AAC.01550-10

7. Shah NS, Auld SC, Brust JCM, Mathema B, Ismail N, Moodley P, et al. Transmission of extensively drug-resistant tuberculosis in South Africa. N Engl J Med. 2017;376:243-53. https://doi.org/10.1056/NEJMoa1604544

8. Martín A, Herranz M, Ruiz Serrano MJ, Bouza E, García de Viedma D. The clonal composition of Mycobacterium tuberculosis in clinical specimens could be modified by culture. Tuberculosis (Edinb). 2010;90:201-7. https://doi.org/10.1016/ j.tube.2010.03.012

9. Operario DJ, Koeppel AF, Turner SD, Bao Y, Pholwat S, Banu S, et al. Prevalence and extent of heteroresistance by next generation sequencing of multidrug-resistant tuberculosis. PLoS One. 2017;12:e0176522. https://doi.org/10.1371/ journal.pone. 0176522

10. McNerney R, Clark TG, Campino S, Rodrigues C, Dolinger D, Smith L, et al. Removing the bottleneck in whole genome sequencing of Mycobacterium tuberculosis for rapid drug resistance analysis: a call to action. Int J Infect Dis. 2017;56:130-5. https://doi.org/10.1016/j.ijid.2016.11.422

Address for correspondence: Scott K. Heysell, University of Virginia, Infectious Diseases and International Health, PO Box 801337, Charlottesville, VA 22908-1337, USA; email: skh8r@virginia.edu 